\title{
A COMPARATIVE ELECTROCHEMICAL AND ELLIPSOMETRIC STUDY OF IRON ELECTRODES IN DIFFERENT ALKALINE ELECTROLYTES*
}

\author{
O. A. Albani, J. O. Zerbino, J. R. Vilche and A. J. Arvia
}

Instituto de Investigaciones Fisicoquimicas Teóricas y Aplicadas, INIFTA, Casilla de Correo 16, Sucursal 4, 1900 La Plata, Argentina

(Received 19 November 1985; in revised form 4 March 1986)

\begin{abstract}
The electrochemical and ellipsometric responses of iron electrodes in $0.04 \mathrm{M} \mathrm{NaOH}$ and in saturated $\mathrm{Ca}(\mathrm{OH})_{2}$ are investigated at $25^{\circ} \mathrm{C}$, in the potential range where the passivating layer in the absence of oxygen under potential controlled and non-equilibrium conditions is formed. From the correlation of results a composite structure of the passivating layer is envisaged involving an inner layer which is difficult to electroreduce, probably related to $\mathrm{Fe}_{3} \mathrm{O}_{4}$, and an outer gelatinous iron hydroxide layer where a relatively fast, $\mathrm{Fe}$ (II)/Fe(III) redox process can be voltammetrically followed.

The inhibitive properties of saturated $\mathrm{Ca}(\mathrm{OH})_{2}$ as compared to $0.04 \mathrm{M} \mathrm{NaOH}$ are explained through the absorption of $\mathrm{Ca}^{2+}$ ions at the outer plane of the inner part of the passivating film and the corresponding transport of water into the gelatinous part of the passivating film.
\end{abstract}

\section{INTRODUCTION}

The electrochemistry of iron in alkaline electrolytes has been the matter of study for a long time in relation to corrosion and passivation. The literature on the subject up to the end of the 1970 s is reviewed in $\operatorname{Refs}[1,2]$. The corrosion and passivation of iron in base solution are relatively complex processes which are still not fully understood as the composition and structure of prepassive and passivating films are not unambiguously established. However, recent electrochemical, optical and analytical data contribute to elucidate many new aspects of those processes. The anodic oxidation of iron in alkaline solutions implies at least two levels. At the first level iron is converted to hydrous $\mathrm{Fe}(\mathrm{OH})_{2}[3-9]$, and at the second level it yields different oxy-hydroxy-species, depending on the anodization program $[3,8,10-13]$.

The mechanism of iron dissolution in base electrolyte has already been discussed in many publications $[4,6,14-19]$. In strongly alkaline solutions the main reaction product is $\mathrm{HFeO}_{2}^{-}$which has been optically identified[5]. In a secondary reaction $\mathrm{HFeO}_{2}^{-}$yields $\mathrm{Fe}(\mathrm{OH})_{2}$ precipitate. Various growth mechanisms for the anodic films on iron were also proposed. The rate of formation of the more compact anodic layer in contact with the electrode is presumably determined by the rate at which $\mathrm{Fe}^{2+}$ ions produced during the anodic polarization move towards the outer film/solution plane. A parabolic growth law is apparently obeyed $[20,21]$. The rate and characteristics of passivating layer formation on iron in base solution depend considerably on the electrolyte composition, temperature and pressure $[19,22-24]$.

* Paper 02040 presented at the 36th ISE Meeting, Salamanca, 23-28 September 1985.
Rrde data suggest that two different mechanisms for the dissolution and passivation of iron in concentrated aqueous alkaline hydroxide are obeyed depending on whether the temperature is lower than $25^{\circ} \mathrm{C}$ or greater than $50^{\circ} \mathrm{C}[25]$. In situ Raman spectroscopy shows that after oxidation-reduction cycles at $1 \mathrm{mVs}^{-1}$ in $1 \mathrm{M}$ $\mathrm{KOH}, \delta$-FeOOH is produced[13]. During cycling this species is electroreduced to $\mathrm{Fe}_{3} \mathrm{O}_{4}$ which apparently remains as an inactive substance to further cycling. At faster potential sweep rates a poorly adhesive $\alpha$ FeOOH species is predominantly formed. The structure of the passivating layer of iron in neutral and alkaline solutions was described in terms of various models involving juxtaposed layers of different nature $[12-14,26-33]$. In the simplest case, a two-layer structure was assumed, where the inner layer, whose composition was adscribed to $\mathrm{Fe}_{3} \mathrm{O}_{4}$ structure, apparently acts as a barrier layer which limits film growth, but passivity is conferred by an outer hydrous $\mathrm{Fe}_{2} \mathrm{O}_{3}$ layer, likely comprising a gelatinous-type layer. Most of these models were proposed to account for data corresponding to continuous passive layer formation under non-equilibrium conditions.

This paper deals with the formation of the passivating layer produced on iron in base solutions in the absence of oxygen under potential-controlled and non-equilibrium conditions, and with redox reactions occurring within the passivating layer. From the correlation between ellipsometric and voltammetric results conclusions are drawn about the likely composite structure of the passivating layer. The difference between the electrochemical and ellipsometric data in changing the electrolyte from $0.04 \mathrm{M} \mathrm{NaOH}$ to saturated $\mathrm{Ca}(\mathrm{OH})_{2}$, is explained through the inhibitive properties of $\mathrm{Ca}(\mathrm{OH})_{2}$ solutions. The adsorption of $\mathrm{Ca}^{2+}$ ions at the outer plane of the inner part of the passivating film means an excess of water transported by $\mathrm{Ca}^{2+}$ as compared to $\mathrm{Na}$ ions into the gelatinous part of the passivating film. 


\section{EXPERIMENTAL}

A high purity polycrystalline iron disc ("Specpure", Johnson Matthey Chemicals Ltd, $0.785 \mathrm{~cm}^{2}$ apparent area) supported on a PTFE holder was used as working electrode. Previously, the iron disc was gradually polished starting from 400 and 600 grade emery papers and finished with $1.0,0.3$ and $0.05 \mu$ alumina on polishing cloth (Microcloth). Finally, the electrode was repeatedly rinsed in thrice distilled water. Before each measurement the electrode was held for $5 \mathrm{~min}$ at $E=$ $-1.36 \mathrm{~V}$, that is in the hydrogen evolution potential region. Potentials were measured employing a hydrogen reference electrode immersed in the same electrolyte solution but in the text they are referred to the nhe scale. The counterelectrode was a spiral shape platinum wire previously cleaned following conventional procedures. The three electrodes were mounted in a three compartment electrolysis glass cell where the iron electrode was horizontally placed into the main cell compartment provided with two plane glass windows adequate for ellipsometric measurements.

Two different electrolyte solutions at $\mathrm{pH} 12.6$ were used, namely saturated $\mathrm{Ca}(\mathrm{OH})_{2}$ solution and $0.04 \mathrm{M}$ $\mathrm{NaOH}$. They were prepared from a.r. (p.a. Merck) reagents and thrice distilled water, previously boiled to remove $\mathrm{CO}_{2}$. Runs were made at $25^{\circ} \mathrm{C}$ under purified $\mathrm{N}_{2}$ gas saturation. The electrolysis cell was mounted in a Rudolph Research type 437-02/200 B manual ellipsometer (maximum resolution $0.01^{\circ}$ ) provided with a $150 \mathrm{~W}$ tungsten lamp with filter (5461 A) and a RCA $1 P 21$ photomultiplier. The incidence light beam angle was fixed at $69^{\circ}$ and that of the compensator at $135^{\circ}$. Ellipsometric data at fixed wavelength of a polished iron electrode held at $E=-1.36 \mathrm{~V}$ were initially measured. The corresponding readings at the polarizer $\left(P_{0}\right)$ and at the analyzer $\left(A_{0}\right)$ yield the refractive index $\left(n_{s}\right)$ and the absorption coefficient $\left(k_{s}\right)$. The complex refractive index, $\bar{n}_{s}=n_{s}-i k_{s}$, derived from $P_{\mathrm{o}}$ and $A_{\mathrm{o}}$ coincides with values reported in the literature for the base iron surface at $5641 \AA[34,35]$.

The ellipsometric readings ( $P$ and $A$ ) of the electrode covered with the anodic layer were made in three different ways. Procedure A consists in the growth of the anodic layer under either a single (stps) or a repetitive (rtps) triangular potential sweep at a fixed scan rate $(v)$ in the $0.02 \mathrm{~V} \mathrm{~s}^{-1} \leqslant v \leqslant 20 \mathrm{~V} \mathrm{~s}^{-1}$ range between the cathodic $\left(\boldsymbol{E}_{s, c}\right)$ and anodic $\left(\boldsymbol{E}_{s, a}\right)$ switching potentials and the ellipsometric readings were made by holding the potential a certain time $(\tau)$ included in stps and $r t p s$ at either $E_{s, c}$ or $E_{s, a}$. In procedure B after a certain potential cycling time, the current was switched off $(t=0)$ either at $E_{s, c}$ or $E_{s, e}$ and the values of $P$ and $A$ were read at different times $(t)$. In the rtps measurements, the potential scan was followed again from the corresponding open circuit potential. Procedure $\mathrm{C}$ consists in reading $P$ and $A$ values during the potential sweep at $2 \mathrm{mV} \mathrm{s}^{-1}$.

\section{RESULTS}

\section{Voltammetric data}

The stps voltammograms of freshly polished iron electrode, run in saturated $\mathrm{Ca}(\mathrm{OH})_{2}$ solution between $E_{s, c}=-1.26 \mathrm{~V}$ and $E_{s, a}=0.54 \mathrm{~V}$ at different $v$ (Fig. 1)

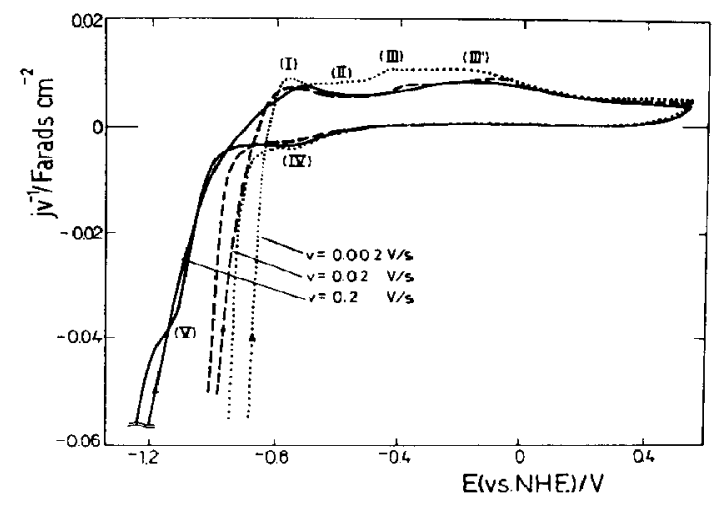

Fig. 1. Single triangular potential sweep voltammograms at different $v$ run in saturated $\mathrm{Ca}(\mathrm{OH})_{2}$ between $E_{s, c}=-1.26 \mathrm{~V}$ and $E_{s, a}=0.54 \mathrm{~V}$ after holding the potential during $10 \mathrm{~min}$ at $E_{s, c}$.

exhibit various ill-defined anodic peaks (I, II, III and III') during the positive potential going scan, and two cathodic contributions (IV and V) during the reverse scan. The identification of the current peaks follows that used in previous publications referred to the voltammetric response of iron in strongly alkaline media $[4,6]$. The pseudocapacitance/potential $\left(j v^{-1} / E\right)$ plots (Fig. 1) show that the anodic charge increases and the cathodic reactions become apparently more reversible as $v$ decreases. On the other hand, the voltammograms continuously modify during cycling (Fig. 2) as indicated by the arrows. These changes are accompanied by the shift in the potential of peaks I, III, IV and V, and the appearance of a new cathodic current contribution (IV'). Likewise, a correlation bet ween the gradual changes of peaks III and IV and humps III' and IV' is noticed.

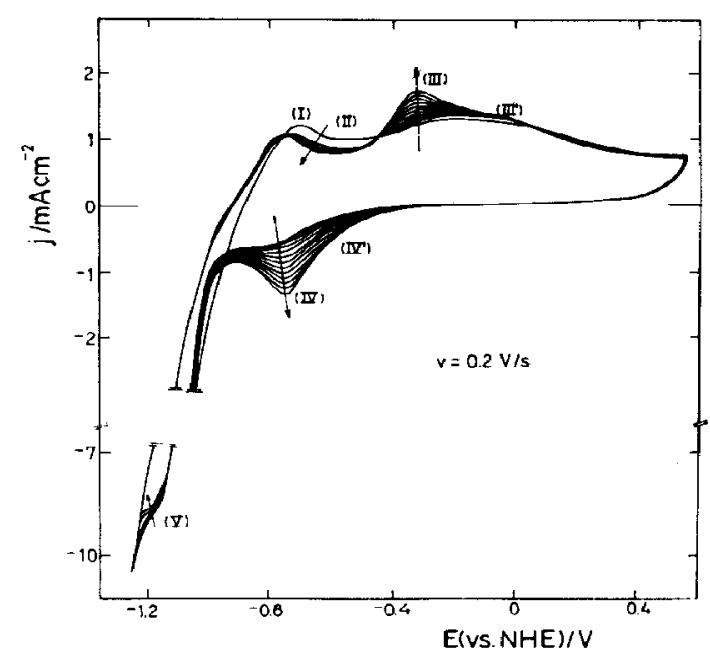

Fig. 2. Repetitive voltammograms run in saturated $\mathrm{Ca}(\mathrm{OH})_{2}$ at $0.2 \mathrm{~V} \mathrm{~s}^{-1}$ between $E_{s, c}=-1.26 \mathrm{~V}$ and $E_{s, a}=0.54 \mathrm{~V}$. The 1 st to 12 th cycle are shown. 


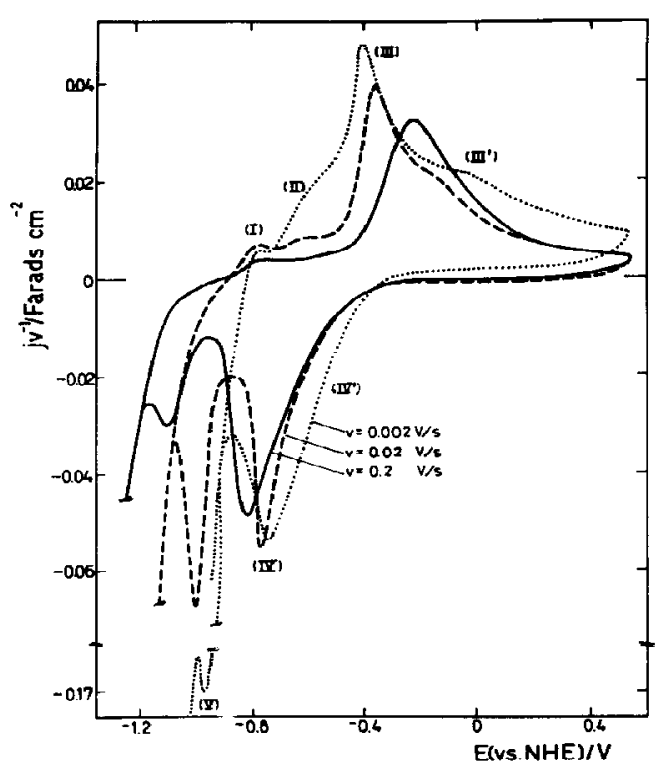

Fig. 3. Pseudocapacitance vs potential plots resulting in saturated $\mathrm{Ca}(\mathrm{OH})_{2}$ after 100 potential cycles at different $v$ hetween $E_{\mathrm{s}, \mathrm{c}}=-1.26 \mathrm{~V}$ and $E_{\mathrm{s}, \mathrm{u}}=0.54 \mathrm{~V}$.

Stabilized voltammograms at $0.2 \mathrm{~V} \mathrm{~s}^{-1}$ result after running approximately 100 potential cycles (Fig. 3). In this case, the corresponding charge is comparatively larger than that resulting from the initial voltammogram. This charge difference indicates the accumulation of the anodically formed surface layer during cycling. The accumulated charge is principally related to the pair of peaks III-III' and IV-IV'. The voltammograms recorded after 10 min cathodization at $E_{s, c}$ between each triangular potential scan are slightly different of the first voltammogram and, accordingly, no charge accumulation can be noticed (Fig. 4a). However, as the intermediate cathodization at $E_{s, c}$ is suppresed the charge accumulation during cycling immediately appears (Fig. 4b).

The voltammogram of iron in $0.04 \mathrm{M} \mathrm{NaOH}$ is similar to that described in Figs $1-4$, although in this case the accumulation of charge is faster than in saturated $\mathrm{Ca}(\mathrm{OH})_{2}$. Furthermore, the voltammetric charge derived from the stabilized voltammogram in $0.04 \mathrm{M} \mathrm{NaOH}$ is greater than that obtained in saturated $\mathrm{Ca}(\mathrm{OH})$. Likewise, in those measurements where the rtps includes a potential holding at $E_{s, c}$, the time of the potential holding required to suppress the charge accumulation effect in $0.04 \mathrm{M} \mathrm{NaOH}$ is slightly longer than in saturated $\mathrm{Ca}(\mathrm{OH})_{2}$.

\section{Ellipsometric data}

For saturated $\mathrm{Ca}(\mathrm{OH})_{2}$ the values $P$ and $A$ determined at different $E_{s, a}$ following procedure $A$, for $\tau=1 \mathrm{~min}$ and $E_{\mathrm{s}, \mathrm{c}}=1.36 \mathrm{~V}$, depend on $v$ (Fig. 5a). Thus, at a constant $v$, the $P$ is $A$ plot moves in the clockwise direction as $E_{s, a}$ is stepwise made more positive. For a constant $E_{s, a}$ value, the $P$ vs $A$ plot



Fig. 4. Voltammograms run in saturated $\mathrm{Ca}(\mathrm{OH})_{2}$ at $0.2 \mathrm{~V} \mathrm{~s}^{-1}$ between $E_{s, c}=1.26 \mathrm{~V}$ and $E_{s, a}=0.54 \mathrm{~V}$. (a) rtps combined with potential steps at $E_{s . c}$ during $\tau=10 \mathrm{~min}$; (b) rtps after 20 potential cycles under the experimental conditions of (a).

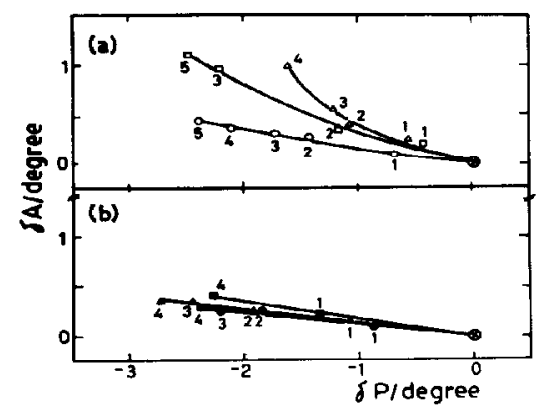

Fig. 5. $P$ vs $A$ plots measured at $E_{s, a}$ after a potential scan from $E_{s, c}=-1.36 \mathrm{~V}$ up to $E_{s, a}$ (a) Saturated $\mathrm{Ca}(\mathrm{OH})_{2} ;$ (b) $0.04 \mathrm{M}$ NaOH. The numbers correspond to the following $E_{s, a}$ values. $-0.56 \mathrm{~V}(1) ;-0.26 \mathrm{~V}(2) ;-0.11 \mathrm{~V}(3) ; 0.01 \mathrm{~V}(4) ;$ and $0.11 \mathrm{~V}$ (5). (o) and (o) $v=20 \mathrm{~V} \mathrm{~s}^{-1}$; ( $\square$ ) and (A) $v$ $=0.02 \mathrm{Vs}^{-1} ;(\Delta)$ and $(\Delta) v=0.002 \mathrm{Vs}^{-1} .(\otimes)$ identifies freshly electroreduced iron electrode held $10 \mathrm{~min}$ at $-1.36 \mathrm{~V}$.

becomes smoother as $v$ increases. The same qualitative behaviour of the $P$ vs $A$ plot is noticed for $0.04 \mathrm{M}$ $\mathrm{NaOH}$, although in this case the influence of $v$ is considerably smaller than that observed in saturated $\mathrm{Ca}(\mathrm{OH})_{2}$ (Fig. 5b).

The ellipsometric parameters change in a different way when they are measured after a potential scan at $20 \mathrm{~V} \mathrm{~s}^{-1}$ from $E_{s, c}=-1.36 \mathrm{~V}$ up to different $E_{s, a}$ values, followed by a potential holding at $E_{s, a}$ for a certain time $\tau$ to accumulate anodic product (Fig. 6). In this case, the ellipsometric plot for $0.04 \mathrm{M} \mathrm{NaOH}$ 
moves with a negative slope as $\tau$ increases, whereas for saturated $\mathrm{Ca}(\mathrm{OH})_{2}$ the opposite trend is observed (Fig. 6).

The ellipsometric data resulting from procedure A, by following the change of $P$ through the variation of the light intensity $[36,37]$, show that $P$ decreases as the charge $(Q)$ accumulated at $0.46 \mathrm{~V}$ increases (Fig. 7). For this purpose the iron electrode immersed in $0.04 \mathrm{M}$ $\mathrm{NaOH}$ was perturbed at $20 \mathrm{~V} \mathrm{~s}^{-1}$ from $-1.26 \mathrm{~V}$ up to $0.46 \mathrm{~V}$ and, immediately afterwards, the potential was held at $0.46 \mathrm{~V}$ for a short time $\tau(0.05 \mathrm{~s} \leqslant \tau \leqslant 5 \mathrm{~s})$. In this case, initially $(\tau<2$ s) $P$ decreases linearly with time and for $\tau>2 \mathrm{~s}$ it approaches a limiting value. At longer times, the ellipsometric plot attains the behaviour shown in Fig. 6. It is also clear that once the limiting value of $\boldsymbol{P}$ has been reached, the latter is

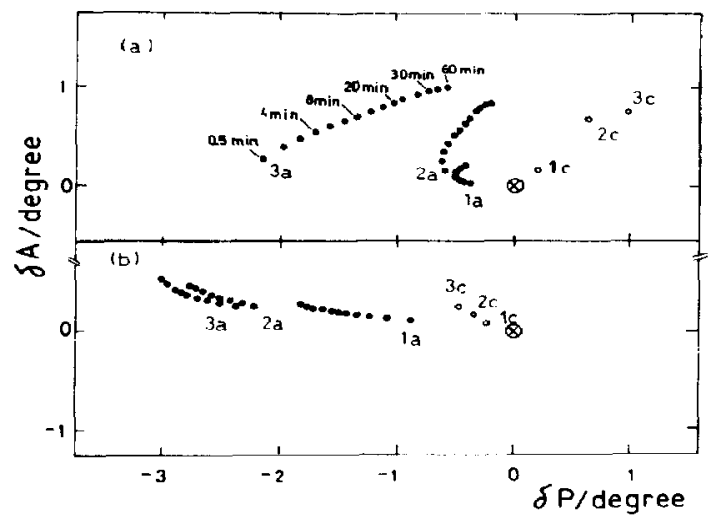

Fig. 6. $P$ vs $A$ plots resulting for the iron electrode previously subjected to rtps at $20 \mathrm{~V} \mathrm{~s}^{-1}$ from $E_{s, c}=-1.36$ (open points denoted by the letter c) and then potential stepped at $E_{s, a}$ (full points denoted by the letter a) during different times: $0.5 \mathrm{~min}$, $4 \mathrm{~min}, 8 \mathrm{~min}, 20 \mathrm{~min}, 30 \mathrm{~min}, 60 \mathrm{~min}$. (a) Saturated $\mathrm{Ca}(\mathrm{OH})_{2}$ : $E_{s, a}=-0.540 \mathrm{~V},-0.440 \mathrm{~V}, 0.225 \mathrm{~V}$. (b) $0.04 \mathrm{M} \mathrm{NaOH} ; E_{s, 0}$ $=-0.440 \mathrm{~V}, 0.010 \mathrm{~V}, 0.125 \mathrm{~V}$.

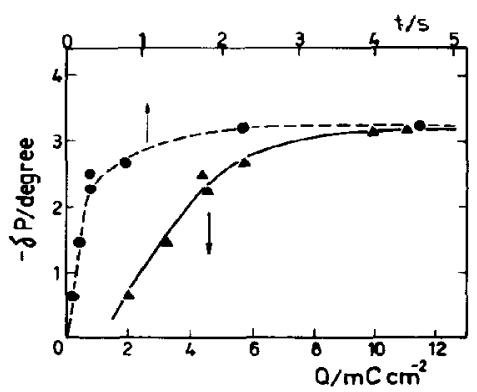

Fig. 7. Dynamic ellipsometric measurements performed in $0.04 \mathrm{M} \mathrm{NaOH}$ according to the procedure described in Refs $[36,37]$. The $P$ vs $t$ and $P$ vs $Q$ plots correspond to potentiostatic measurements at $E_{s, a}=0.46 \mathrm{~V}$ during different times after a potential sweep at $20 \mathrm{~V} \mathrm{~s}^{-1}$ starting from $E_{s, c}=$ -1.26 V. $P$ indicates the optical change from the initial base metal at $E_{s, c}$ to the metal covered by the passivating film under open circiut condition. slightly influenced by further increasing the anodic charge. Large changes in $P$ correspond to relatively thin anodic layers. Runs made in saturated $\mathrm{Ca}(\mathrm{OH})$ show the same $P$ vs $Q$ dependence for $\tau<5 \mathrm{~s}$.

The ellipsometric data gradually change during the successive potential cycling (Fig. 8), but the direction and magnitude of these changes are remarkably dependent whether the clectrolyte is saturated $\mathrm{Ca}(\mathrm{OH})_{2}$ (Fig. 8a) or $0.04 \mathrm{M} \mathrm{NaOH}$ (Fig. 8b). These differences also resemble the behaviour shown in Fig. 6 under a different potential perturbation program.

Ellipsometric measurements in saturated $\mathrm{Ca}(\mathrm{OH})_{2}$ were also made under procedure $B$ for $t=1 \mathrm{~min}$ open

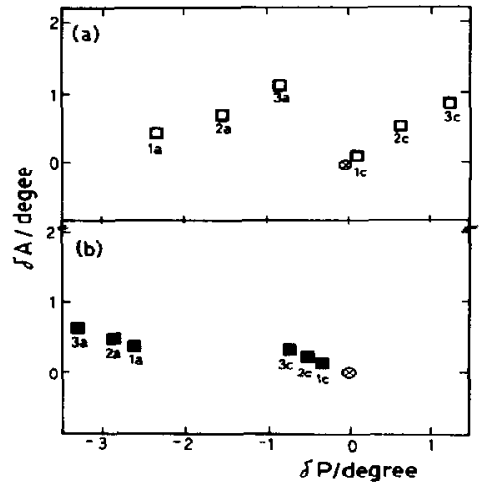

Fig. 8. $P$ vs $A$ plots for the surface film at $E_{s, a}=0.01 \mathrm{~V}$ (points denoted by the letter a) and $E_{s, c}=-1.26 \mathrm{~V}$ (points denoted by the letter c) during the $1 \mathrm{st}, 2$ nd and 3 rd potential scans at $0.2 \mathrm{Vs} \mathrm{s}^{-1}$. (a) Saturated $\mathrm{Ca}(\mathrm{OH})_{2} ;$ (b) $0.04 \mathrm{M} \mathrm{NaOH}$.

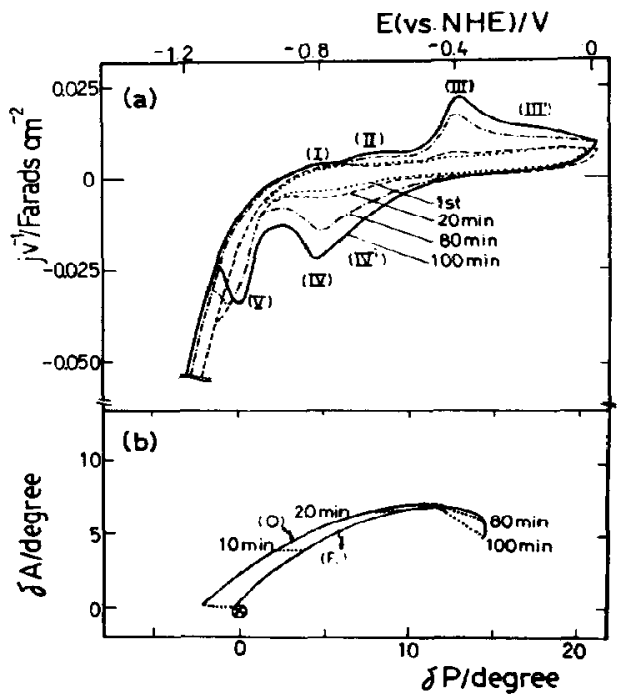

Fig. 9. (a) Voltammograms obtained in saturated $\mathrm{Ca}(\mathrm{OH})_{2}$ under rtps at $0.04 \mathrm{~V} \mathrm{~s}^{-1}$ between $E_{s, c}=-1.36 \mathrm{~V}$ and $E_{s, e}$ $=0.01 \mathrm{~V}$. The first cycle and the voltammograms after $20 \mathrm{~min}, 80 \mathrm{~min}$ and $100 \mathrm{~min}$ potential cycling are shown. (b) $P$ $v s A$ plots made with data resulting at $E_{s . a}$ and $E_{s, c}$ along the rtps perturbation indicated in (a). 
circuit conditions for cycling times up to $100 \mathrm{~min}$ (Fig. 9). In this case, the voltammetric charges related to peaks III and IV increase according to the cycling time, whereas those related to peaks I, II and V remain practically constant (Fig. 9a). The corresponding $P$ vs $A$ plot (Fig. 9b) exhibits two envelopes moving clockwise as the voltammetric charge increases. One envelope measured at $E_{s, \alpha}$ corresponds to the oxidized state of the passivating layer, whereas the other one determined at $E_{s, r}$ belongs to the reduced state. The change in the ellipsometric parameters are more remarkable during the initial $20 \mathrm{~min}$ of rtps. Comparable experiments made in $0.04 \mathrm{M} \mathrm{NaOH}$ (Fig. 10) present the same qualitative features described for saturated $\mathrm{Ca}(\mathrm{OH})_{2}$, although the accumulation of charge during rtps in $0.04 \mathrm{M} \mathrm{NaOH}$ (Fig. 10a) is greater than in saturated $\mathrm{Ca}(\mathrm{OH})_{2}$. The above referred voltammetric charge difference becomes more noticeable in the $P$ vs $A$ plot (compare results shown in Figs $9 \mathrm{~b}$ and 10b). The outer loop (oxidized state) and the inner loop (reduced state) also move clockwise along the potential cycling, but only for $0.04 \mathrm{M} \mathrm{NaOH}$ the initial portion of the plot has a negative slope. Moreover, there is a remarkable difference between values of $P$ and $A$ mcasurcd at $E_{s, a}$ and $E_{s, c}$ after a constant potential cycling time. These runs demonstrate that under the experimental conditions of Figs 9 and 10, the anodic layer accumulated during the potential cycling is not completely electroreduced during the negative potential going scan. Furthermore, the anodically formed layer exhibits different properties in the oxidized and the reduced forms. Both the growth rate and the optical properties of the anodically formed layer depend considerably, therefore, on the electrolyte composition.

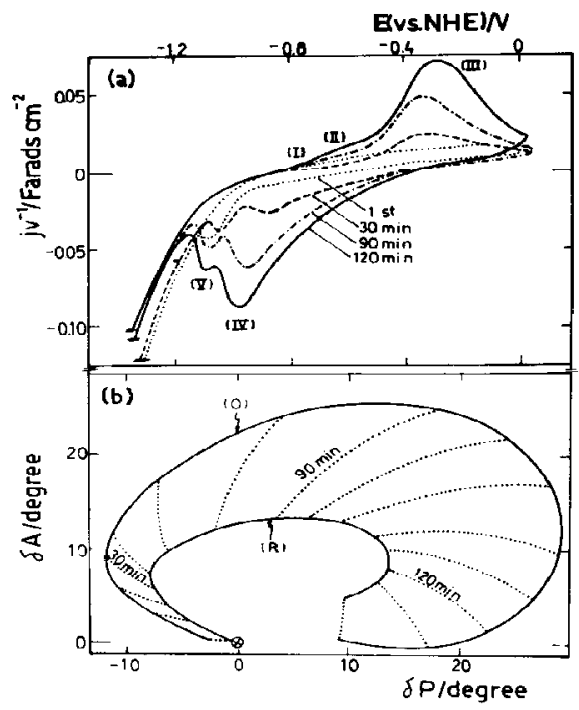

Fig. 10. (a) Voltammograms obtained in $0.04 \mathrm{M} \mathrm{NaOH}$ under rtps at $0.04 \mathrm{~V} \mathrm{~s}^{-1}$ between $E_{s_{1},}=-1.36 \mathrm{~V}$ and $E_{s, a}$ $=0.01 \mathrm{~V}$. The first cycle and the voltammograms after $30 \mathrm{~min}, 90 \mathrm{~min}$ and $120 \mathrm{~min}$ potential cycling are presented. (b) $P$ vs $A$ plots made with data resulting at $E_{s, a}$ (external loop) and $E_{s, c}$ (inner loop) along the $r t p s$ perturbation indicated in (a).
The changes in $P$ and $A$ under extinction conditions were also determined from procedure $\mathrm{C}$ at $v$ $=0.002 \mathrm{~V} \mathrm{~s}^{-1}$ after a previous $20 \mathrm{~min}$ rtps at $0.2 \mathrm{~V} \mathrm{~s}^{-1}$ (Fig. 11), that is for a relatively large amount of anodically formed layer. In this case, the dynamic ellipsometric measurements were made at a potential sweep rate sufficiently low so that the time for the optical measurements was in the $\pm 0.01 \mathrm{~V}$ range of the potential sweep. In $0.04 \mathrm{M} \mathrm{NaOH}$ large hysteresis loops for both $A$ and $P$ are recorded for $E_{s, c}$ more negative than the potential of peak IV and $E_{s, a}$ more positive than the potential range of peak IiI. The hysteresis is enhanced on continuing the potential cycles. For saturated $\mathrm{Ca}(\mathrm{OH})_{2}$, where the charge accumulation during cycling is appreciably lower than for $0.04 \mathrm{M} \mathrm{NaOH}$, the hysteresis loop under comparable conditions is remarkable smaller than in $0.04 \mathrm{M} \mathrm{NaOH}$. In the latter, the difference in size of the end point loops shows that the oxidized form of the film has a higher index than the reduced form. Comparative dynamic measurements of $P$ and $A$, at $0.002 \mathrm{Vs}^{-1}$, between an electrode which has been previously cycled $20 \mathrm{~min}$ at $0.04 \mathrm{~V} \mathrm{~s}^{-1}$ (Fig. 12a) and a freshly polished electrode (Fig. 12b), reveal that the optical data strongly depcnd on the history of the electrode (Fig. 12b). For a fresh electrode the $P$ vs $A$ plot exhibits a relatively low hysteresis loop and the initial slope is always negative for the potential scanning in both directions. Conversely, when a relatively large amount of product was accumulated on the

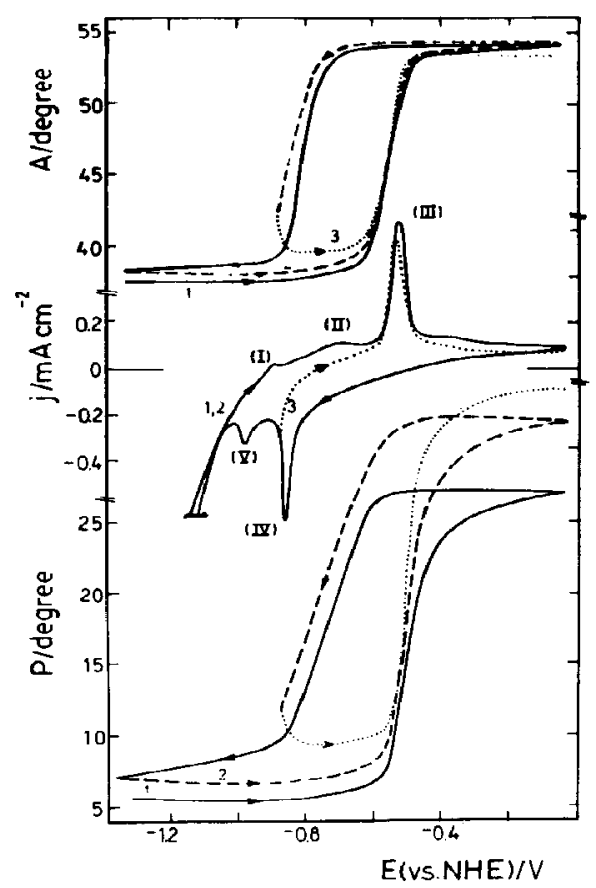

Fig. 11. $P$ vs $E$ and $A$ vs $E$ plots under extinction conditions measured in $0.04 \mathrm{M} \mathrm{NaOH}$ at $0.002 \mathrm{~V} \mathrm{~s}^{-1}$ after $20 \mathrm{~min}$ potential cycling at $0.2 \mathrm{~V} \mathrm{~s}^{-1}$ between $E_{s, c}=-1.36 \mathrm{~V}$ and $E_{s, a}=0 \mathrm{~V}$. Dotted lines correspond to the electrochemical and ellipsometric responses after setting $E_{s, c}$ at $-0.88 \mathrm{~V}$. 


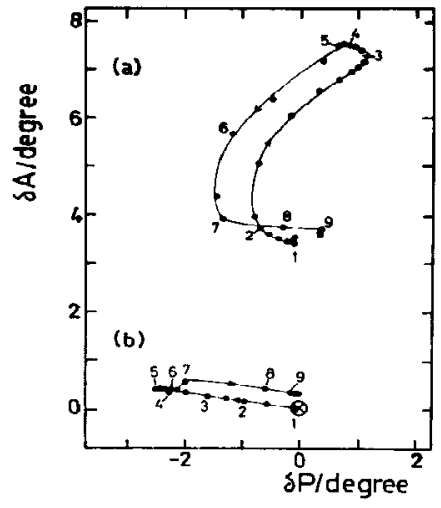

Fig. 12. $P$ vs $A$ plots obtained at different potentials in $0.04 \mathrm{M}$ $\mathrm{NaOH}$ during a potential sweep at $0.002 \mathrm{~V} \mathrm{~s}^{-1}$ between $E_{\mathrm{s}, c}$ $=-1.36 \mathrm{~V}$ and $E_{s, a}=0.01 \mathrm{~V}$. (1) $E=-1.31 \mathrm{~V}$; (2) $E=$ $-0.44 \mathrm{~V}$; (3) $E=-0.20 \mathrm{~V}$; (4) $E=0.01 \mathrm{~V}$; (5) $E=-0.15 \mathrm{~V}$; (6) $E=-0.76 \mathrm{~V}$; (7) $E=-0.89 \mathrm{~V}$; (8) $E=-0.97 \mathrm{~V}$; (9) $E=$ $-1.02 \mathrm{~V}$. The ellipsometric readings correspond to the following conditions: (a) after a previous $30 \mathrm{~min}$ potential cycling at $0.04 \mathrm{~V} \mathrm{~s}^{-1}$; (b) the first potential scan with a freshly polished electrode.

clectrode a remarkable hysteresis loop in the $P$ vs $A$ plots is found. There is also a change in the slope of the plots from a negative to a positive value as the applied potential moves in the positive direction. These results confirm that the initial layer of products behaves differently to the thick layer accumulated during rtps.

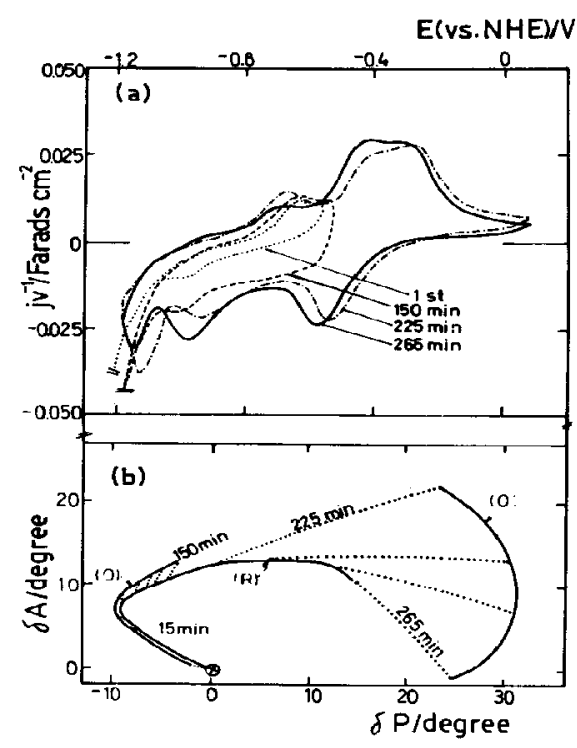

Fig. 13. (a) Voltammograms obtained by cycling between $E_{s, c}=-1.36 \mathrm{~V}$ and $E_{s, a}=-0.53 \mathrm{~V}$ at $v=40 \mathrm{mV} \mathrm{s}^{-1}$. After $150 \mathrm{~min} r t p s$ the anodic potential limit was changed to $E_{s . a}$ $=0.08 \mathrm{~V}$. (b) $P$ vs $A$ plots corresponding to readings at $E_{s, a}$ (external loop) and $E_{s . c}$ (inner loop) along the rtps perturbation indicated in (a).
This difference is verified through rtps voltammetric-ellipsometric runs made at $0.04 \mathrm{~V} \mathrm{~s}^{-1}$ from $E_{s, c}$ to $E_{s, a}$ values covering either the potential range of peaks I, II and $\mathrm{V}$ or the potential range of peaks I, II, III, IV and $V$ (Fig. 13). For $E_{s, a}=-0.53 \mathrm{~V}$ the ellipsometric parameters resulting at $E_{s, a}$ and $E_{s, c}$ are very close even for $150 \mathrm{~min}$ potential cycling (Fig. 13b). This suggests that as the layer formed at low potentials $\left(E_{s, a}=-0.53 \mathrm{~V}\right)$ is thinner than that obtained for $E_{s, a}$ $=0.01 \mathrm{~V}$ (Fig. 10) under comparable experimental conditions, the cathodic products are only partially electrooxidized at $E_{s, a}$. Therefore, the ellipsometric properties of the oxidized and reduced states of the passivating layer are nearly the same. The reverse effect is observed for the ellipsometric properties of the thick layer produced for $E_{s, a}=0.08 \mathrm{~V}$. In this case, very remarkable, different ellipsometric properties of the oxidized and reduced states are observed. It should be noticed, however, that the ellipsometric data of the reduced state whether it comes from thin or thick oxidized layers, fit, in principle, the same $P$ vs $A$ plot, but this is not the case for the oxidized state. Therefore, one concludes that two different types of oxidized oxyhydroxide layers are produced, depending on whether $E_{s, a}$ lies in the potential range of peaks I and II or in the potential range of peaks III and III'. The above described features applied to both electrolyte solutions although the effects in $0.04 \mathrm{M} \mathrm{NaOH}$ are more remarkable than in saturated $\mathrm{Ca}(\mathrm{OH})_{2}$.

\section{DISCUSSION}

The electrochemical and ellipsometric results of iron electrodes are considerably dependent on the electrolyte composition. For each electrolyte solution employed in the present study the time dependence of the voitammetric responses also reffects in the ellipsometric results. Thus, during the first anodic potential scan ill-defined peaks are observed (Fig. 1) and the charge involved is relatively small. The complete electroreduction or removing of the anodic products can be achieved provided that the voltammetric scan includes a certain cathodization time at $E_{s, c}$ (Fig. 4). The cathodization time depends on both $E_{s, a}$ and the holding time at $E_{s, a}$. Therefore the conventional rtps voltammograms show the accumulation of anodic products on the electrode surface during cycling (Fig. 2). The rate of charge accumulation which is strongly influenced by $E_{s, c}, E_{s, a}, v$, cycling time and electrolyte composition, is associated with both the gradual modification of the conjugated pair of peaks III-III'/IV-IV' and the change in the ellipsometric coordinates (Figs 9 and 10). On the other hand, it should be noticed that the charge involved in peaks I, II and $\mathrm{V}$ remains practically unaltered during cycling. These results and those from ellipsometry (Fig. 5) suggest that the anodic product implies an inner layer which is electroreduced in the potential range of peak $V$ and an outer layer which grows during $r$ tps. Optical data obtained at high $v$ and short holding times at $E_{s, a}$ and first voltammograms show that the inner layer properties apparently are independent of the solution composition. The influence of the electrolyte composition appears during the first potential sweep at low scan rates as the outer layer grows (Fig. 5) and also at 
fast scan rates after large holding times at $E_{s, a}$ (Fig. 6).

The charge involved in the formation of the inner layer is considerably smaller than that related to the growth of the outer layer (Fig. 7). Even for relatively high positive potentials, the linear relationship observed in the short time range between $\delta P$ and either holding time at $E_{s, a}$ or anodic charge can be explained through the inner layer formation. The latter implies large changes in the value of $P$ at relatively short time, smaller than $0.5 \mathrm{~s}$. For times longer than $2 \mathrm{~s}$, the value of $\boldsymbol{P}$ remains practically constant and in this case the charge increase can be assigned to the transport of $\mathrm{Fe}(\mathrm{II})$ ions through the inner layer contributing to the growth of the outer layer.

The different behaviour of iron in $0.04 \mathrm{M} \mathrm{NaOH}$ and saturated $\mathrm{Ca}(\mathrm{OH})_{2}$ under repetitive potential scanning (Figs 6 and 8 ) reflects through the accumulated anodic product remaining at $E_{s, c}$, which exhibits optical properties considerably depending on the electrolyte composition. This difference can be associated with distinguishable structures for the outer layer formed in each electrolyte solution. The $P$ vs $A$ plots for each solution resulting from the application of procedure A, for holding times at $E_{s, a}$ larger than $2 \mathrm{~s}$, differ in the time-dependence of the optical constants (Fig. 6), although for a fixed $E_{s, a}$ the shift of the optical constants becomes quantitatively similar to that obtained during potential cycling (Fig. 8). These results indicate that the growth of the outer layer can be achieved either by holding the potential at $E_{s . a}$ or by potential cycling.

It is interesting to emphasize that at the initial stages of the passive film formation, the influence of the electrolyte composition on the ellipsometric characteristics (Fig. 8) correlates with the loops of the $P$ vs $A$ plots resulting at prolonged rtps (Figs $9 \mathrm{~b}$ and 10b). As the inner layer is completely electroreduced at sufficiently negative potentials, $E_{s, c}=-1.36 \mathrm{~V}$, the remaining passivating film (Figs 9 and 10 ) can be directly associated with the electroreduced state of the outer layer. Under these conditions, the difference in the ellipsometric readings resulting during the potential cycling can be discussed in terms of a simple single film model. For this purpose theoretical $P$ is $A$ plots are simulated for constant refractive indices covering wide ranges of the absorption coefficient and average optical thickness of the single film (Fig. 14) according to the program developed by McCracking[38]. For thin films, the $P$ vs $A$ plot is practically linear and the extent of this linear portion increases with increasing $n$ values. Accordingly, the clockwise loop recorded for thick films in both electrolytes covers wider $\delta P$ and $\delta A$ ranges as $\boldsymbol{n}$ increases.

The barrier layer initially formed has been associated with $n \geqslant 2.2[27-29]$. These high $n$ values were interpreted in terms of a low water content highdensity, non-porous oxide film. The primary passivity layer was identified as $\mathrm{Fe}_{3} \mathrm{O}_{4}[9,13]$. However, depending on the solution $\mathrm{pH}$, the barrier layer can be assumed either as a single or a duplex barrier oxide structure. The ellipsometric results obtained at pH 12.6 (Figs 5-13) can, in principle, be adequately interpreted by a single inner layer model.

The single film model (Fig. 14) can be extended to a model involving the two superposed different homogeneous oxide layers. In this case, the values of the optical

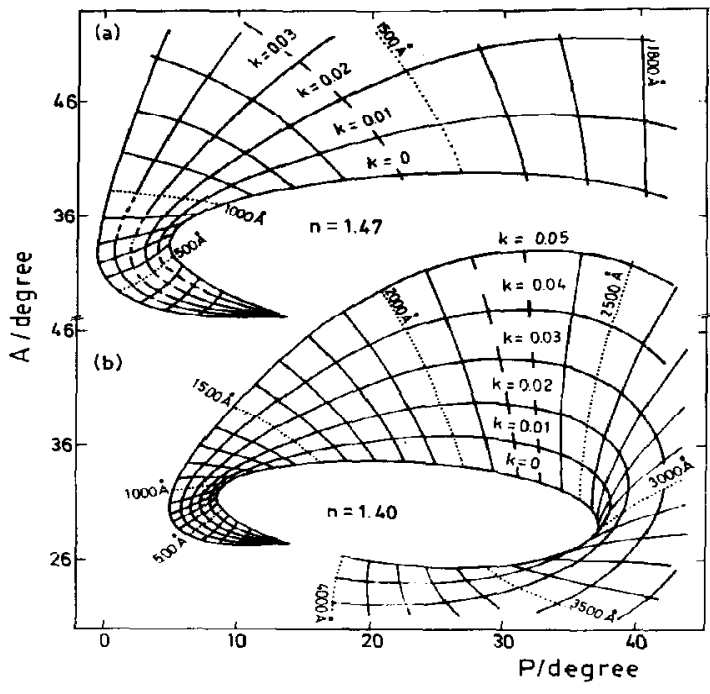

Fig. 14. Theoretical $P$ vs $A$ plots computed for $n=1.47$ (a) and $n=1.40$ (b) for different $k$ and film thickness values, on the basis of a single layer model[38].

parameters for the entire layer are taken as the sum of the $\delta P$ and $\delta A$ values for the two films. In this way, as a first approximation, one can explain the electrochemical and ellipsometric behaviour of the inner layer by considering that for each electrolyte its properties are only determined by $E_{s, a}$, and independent of the charge accumulated in the outer layer during cycling. As the global optical parameters (Figs 9 and 10) result as the sum of those of the inner and outer layers, the duplex structure of the passivating layer clearly reflects in the inner and outer loops of the ellipsometric plots (Figs 9 and 10). The inner loop corresponds to the reduced state of the outer layer whereas the outer loop implies its oxidized state plus the inner barrier layer formed at $E_{s, a}$. The change of the optical parameters during cycling associated with the outer layer, can be evaluated after correcting the outer loop for $\delta P$ and $\delta A$ values of the first anodic potential scan at high $v$ (Fig. 5).

In $0.04 \mathrm{M} \mathrm{NaOH}$ solution, the relative contribution of the inner layer to the global $P$ vs $A$ plot decreases during potential cycling (Fig. 10b) and the change in the optical variables between the oxidized and reduced states of the outer layer for comparable potential cycling conditions, can be interpreted as a change in $k$ at a constant thickness (Fig. 14). The ellipsometric response of the reduced state obtained up to $60 \mathrm{~min}$ potential cycling (Fig. 10b) fits a single film model with $n=1.44$ and $0.005 \leqslant k \leqslant 0.010$ for a film thickness continuously increasing up to about $1400 \mathrm{~A}$. For thicker films, $n$ tends to decrease. On the other hand, the voltammetric and the dynamic ellipsometric changes (Fig. 11) reveal that the optical changes in converting the outer layer from the anodized to the reduced state and vice versa are related to the complex voltammetric peaks III and IV. Similar conclusions can be derived by comparing the optical results of the first cycle with those obtained after a prolonged cycling 
(Fig. 12). During the first cycle the changes in the $P$ vs $A$ plot related to the electrooxidation scan (Fig. 12b) can be attributed to the formation of the inner barrier layer and the contribution to the progressive growth of the outer layer is seen during the electroreduction scan at potentials more positive than peak $\mathrm{V}$. After a prolonged cycling, the change in the optical parameters during a single potential scan (Fig. 12a) are presumably related to different contributions, namely, reversible redox reactions at the outer layer, the electroformation and electroreduction of the barrier layer, and the small increase of the outer layer thickness. Under these circumstances the nearly parallel envelopes resulting in the $P$ vs $A$ plot within the potential ranges of peak III and IV, imply the reversible optical response of the outer layer. Furthermore, the separation between the two parallel envelopes should depend nearly exclusively of the inner layer present at $E_{s, a}$. This interpretation of the ellipsometric results is certainly simpler than that advanced earlier in terms of two models for the oxidation and reduction of the outer layer, based on galvanostatic measurements an air saturated $0.05 \mathrm{M}$ $\mathrm{NaOH}[33]$. For $E_{\text {s.a }}$ more negative than the potential of peak IIIb (Fig. 13) the outer layer either formed during cycling or resulting from the electroreduction of the inner barrier layer remains in the reduced state. In this case, the two envelopes are very close together for short potential cycling times (Fig. 13b).

The voltammetric and ellipsometric results obtained in saturated $\mathrm{Ca}(\mathrm{OH})_{2}$ (Fig. $9 \mathrm{~b}$ ) are to some extent qualitatively similar to those resulting in $0.04 \mathrm{M}$ $\mathrm{NaOH}$. The voltammetric profiles clearly show that the accumulation of charge in saturated $\mathrm{Ca}(\mathrm{OH})_{2}$ is considerably smaller than in $0.04 \mathrm{M} \mathrm{NaOH}$. This means that the presence of $\mathrm{Ca}^{2+}$ acts as an inhibitor for the corrosion process, as it has been recognized in previous works $[39,40]$. Furthermore, the potentials of peaks III and IV associated with the redox couple at the outer layer, indicate that the polarization of these reactions, particularly for the electroreduction process, in $0.04 \mathrm{M} \mathrm{NaOH}$ are greater than in saturated $\mathrm{Ca}(\mathrm{OH})_{2}$. The ellipsometric data obtained in saturated $\mathrm{Ca}(\mathrm{OH})_{2}$ are inconsistent with a constant value of $n$ for the thin film initially formed, and it should be assumed that during the first 20 min potential cycling $n$ gradually increases from $n=1.33$, a value close to that corresponding to the electrolyte, up to about 1.44 . This suggests that the ellipsometric response implies a lowdensity oxide structure.

The characteristics of iron in saturated $\mathrm{Ca}(\mathrm{OH})_{2}$ can also be interpreted in terms of the same passivating film model already described for iron in $0.04 \mathrm{M}$ $\mathrm{NaOH}$. The difference in the voltammetric and ellipsometric features obtained for each solution should be related to the difference in the charge/size ratio of $\mathrm{Na}^{+}$ and $\mathrm{Ca}^{2+}$ ions and consequently, in their corresponding hydration energies. On the assumption that the inner part of the passivating layer consists of a $\mathrm{Fe}_{3} \mathrm{O}_{4}$ type film, as it is supported by optical data $[13,33]$ in the positive potential range where the inner passivating layer is formed, the adsorption of $\mathrm{Ca}^{2+}$ ions should become much stronger than that of a $\mathrm{Na}$ ions. The preferential adsorption of $\mathrm{Ca}^{2+}$ ions at the outer plane of the inner oxide film should decrease the strength of the electric field assisting the displacement of iron ions from the substrate through the inner layer to the outer layer region during the potential cycling. On regarding the structure of the passive film as equivalent to two charged capacitors in series, one should expect that the presence of $\mathrm{Ca}^{2+}$ ions produces a decrease of the overall electrode capacitance. This effect has actually been reported in the literature for iron electrodes in alkaline solutions[41]. The adsorbed cations $\mathrm{Ca}^{2+}, \mathrm{Mg}^{2+}$ or $\mathrm{Ba}^{2+}$ displace the electrode potential toward positive values which retards the anodic ionization of iron but accelerates the accumulation of passivating oxides while the first stage of the anodic reaction is taking place and accelerates its passivation.

The presence of $\mathrm{Ca}^{2+}$ ions in the structure of the passivating layer for iron in alkaline solutions was revealed by different analytical techniques. Therefore, the model proposed for describing the passivating layer is consistent with the insertion of ions from the bulk solution into the layer structure[23,43]. The conclusion immediately derived from the proposed structure is that the water content of the outer layer is saturated $\mathrm{Ca}(\mathrm{OH})_{2}$ should be greater than in $0.04 \mathrm{M}$ $\mathrm{NaOH}$. Consequently, the values of $n$ in the former case should be lower than in the latter, as discussed above. The important role played by water in the passivation of iron has been determined from Mössbauer studies of both in situ and dried passive oxide films[42]. In addition, the presence of $\mathrm{Ca}^{2+}$ ion should have a depolarizing effect on the electrochemical reactions occurring at the outer part of the passivating layer. This depolarizing effect must be attributed to a modification of the potential distribution at the reaction interface and to the structure changes produced by the presence of $\mathrm{Ca}^{2+}$ in the passivating layer.

\section{CONCLUSIONS}

(i) The ellipsometric data indicate that in both $0.04 \mathrm{M} \mathrm{NaOH}$ and saturated $\mathrm{Ca}(\mathrm{OH})_{2}$ the passivating layer involves the juxtaposition of an inner and an outer layer.

(ii) The main potential drop is confined to the inner layer thickness.

(iii) The thickness of inner layer increases continuously on increasing the electroformation potential.

(iv) At a constant bulk pH the ellipsometric characteristics of the inner layer are independent of the solution composition.

(v) The inner layer can be completely electroreduced at potentials more negative than that of the hydrogen electrode in the same solution.

(vi) The electroreduction of the inner layer to $\mathrm{Fe}(\mathrm{O})$ involves two parallel reactions and the formation of another product which incorporates into the outer layer. In agreement with galvanostatic results [33] there is no evidence that the inner layer undergoes solid phase oxidation or reduction under voltammetric cycling.

(vii) The inner layer itself probably involves either a complex or a duplex structure.

(viii) The response of the outer layer is extremely dependent on the electrolyte composition and potential perturbation program applied to the iron electrode. 
(ix) The outer layer behaves as a porous hydrous structure, whose thickness increases during the potential cycling. One may think that the outer layer is made of either a very porous film containing considerable electrolyte or a film of electrolyte containing partially dissolved reaction products[33]. These two alternatives are, however, undistinguishable when dealing with a gelatinous structure.

(x) The $\mathrm{Fe}(\mathrm{II}) / \mathrm{Fe}$ (III) couple at the outer layer behaves as a reversible reaction.

(xi) The charge accumulation at the outer layer during cycling is greater in $0.04 \mathrm{M} \mathrm{NaOH}$ than in saturated $\mathrm{Ca}(\mathrm{OH})_{2}$.

(xii) The outer layer formed in $0.04 \mathrm{M} \mathrm{NaOH}$ is apparently more compact than in $\mathrm{Ca}(\mathrm{OH})_{2}$ solution.

(xiii) The characteristics of the outer layer probably depend on the degree of hydration of cations incorporated into its hydrous structure from the bulk of the solution.

Acknowledgements - INIFTA is a research institute jointly established by the Universidad Nacional de La Plata, the Consejo Nacional de Investigaciones Científicas y Técnicas and the Comisión de Investigaciones Cientfficas de la Provincia de Buenos Aires. Part of the equipment used in the present work was provided through the Cooperation Agreement between the University of Mainz (Germany) and the University of La Plata (Argentina).

\section{REFERENCES}

1. G. Nazri, E. Yeager and B. D. Cahan, Tech. Rep. No. 1, Proj. NR SRO-009/7-30-79, Case Western Reserve University, Cleveland (1981).

2. K. E. Heusler, in Encyclopedia of Electrochemistry of the Elements (Edited by A. J. Bard), Vol. 9A, pp. 229-381. Marcel Dekker, New York (1982).

3. L. Öjefors, J. electrochem. Soc. 123, 1691 (1976)

4. R. S. Schrebler Guzmán, J. R. Vilche and A. J. Arvia, Electrochim. Acta 24, 395 (1979); J. appl. Electrochem. 11, 551 (1981); Anal. Asoc. Quim. Arg. 70, 999 (1982).

5. H. Neugebauer, G. Nauer, N. Brinda-Konopik and G. Gidaly, J. electroanal. Chem. 122, 381 (1981).

6. J. R. Vilche and A. J. Arvia, Acta Cient, Venez, 31, 408 (1980); Proc. 7th Inter. Congr. Met. Corrs., pp. 245-266. Rio de Janeiro (1978).

7. D. M. Drazic and C. S. Hao, Electrochim. Acta 27, 1409 (1982).

3. N. Brinda-Konopik, G. Nauer, $H$. Neugebauer and $P$. Schneyder DECHEMA-Monographic, Bd. 92, pp. 207-219. Verlag Chemie, Berlin (1982).

9. J. Dönnwald, R. Lossy and A. Otto, in Passivity of Metals and Semiconductors (Edited by $M$. Froment), pp. 107-112. Elsevier, Amsterdam (1983).

10. I. Olefjord, J. appl. Electrochem. 5, 145 (1975).

11. Y. Geronov, T. Tomov and S. Georgiev, J. appl. Electrochem. 5, 351 (1975).
12. J. L. Ord, in Passivity of Metals and Semiconductors (Edited by M. Froment), pp. 95-100. Elsevier, Amsterdam (1983).

13. J. Dönnwald and A. Otto, Z. Anal. Chem. 319, 738 (1984).

14. M. E. Vela, J. R. Vilche and A. J. Arvia, J. appl. Electrochem., in press.

15. R. D. Armstrong and I. Baurhoo, J. electroanal. Chem. 34, 41 (1972); J. electroanal. Chem. 40, 325 (1972).

16. D. Geana, A. A. El Miligy and W. J. Lorenz, J. appl. Electrochem. 4, 337 (1974).

17. D. D. MacDonald and R. Roberts, Electrochim. Acta 23, 781 (1978).

18. G. T. Burstein and G. W. Ashley, Corrosion 39, 241 (1983).

19. P. K. Chauhan, N. S. D. Elayathu and H. S. Gadiyar, Proc. 8th Inter. Congr. Met. Corros., pp. 236-241. Mainz (1981).

20. T. G. Stepina and Z. A. Iofa, Electrokhimiya 15, 151 (1979).

21. T. G. Stepina, Z. A. Iofa, E. V. Kasatkin, V. A. Shepelin and V. A. Safonov, Elektrokhimiya 16, 1884 (1980).

22. D. S. Poa, J. F. Miller and N. P. Yao, Ext. Abs. 164th Meet. Electrochem. Soc., Washington, pp. 17-18 (1983); Ext. Abs. 166th Meet. Electrochem. Soc., New Orleans, pp. 144-145 (1984).

23. H. Oranowska and Z. Szklarska-Smialowska, Corros. Sci. 21, 735 (1981).

24. J. J. Ritter and J. Kruger, Ext. Abs. 158th Meet. Electrochem. Soc., Hollywood, pp. 615-617 (1980).

25. M. C. H. McKubre and M. J. Madou, Ext. Abs. 163rd Meet. Electrochem. Soc., San Francisco, pp. 81-82 (1983).

26. N. Sato and M. Cohen, J. electrochem. Soc. 111, 512, 519 (1964).

27. J. L. Ord and D. J. DeSmet, J. electrochem. Soc. 113, 1253 (1966); 118, 206 (1971); 123, 1876 (1976).

28. R. Nishimura, K. Kudo and N. Sato, J. Japan. Inst. Metals 45, 581 (1981); Surf. Sci. 96, 413 (1980).

29. R. Nishimura and N. Sato, Corros. Engng Japan 30, 456 (1981); Proc. 9th Inter. Congr. Met. Corros., Vol. 1, pp. 96-101. Toronto (1984).

30. B. D. Cahan and C. T. Chien, J. electrochem. Soc. 129, 17, 474, 921 (1982).

31. K. Ogura, A. Fijishima and K. Honda, J. electrochem. Soc. 131, 344 (1984); J. electroanal. Chem. 162, 241 (1984)

32. W. Kozlowski and A. Szklarska-Smialowska, J. electrochem. Soc. 131, 234, 499, 723 (1984).

33. Z. Q. Huang and J. L. Ord, J. electrochem. Soc. 132, 24 (1985).

34. N. Sato and K. Kudo, Electrochim. Acta 16, 447 (1971).

35. N. Sato, Boshoku Gijutsu 23, 535 (1974).

36. V. Brusic, M. Genshaw and B. Cahan, J.opt. Soc. 9, 1634 (1970).

37. J. O'M. Bockris, M. Genshaw and V. Brusic, Symp. Faraday Soc. 4, 177 (1970).

38. F. L. McCracking, Nat. Bur. Stand. Tech. Note 479, U.S. Govt. Printing Office, Washington (1969).

39. V. K. Gouda, Br. corros. J. 5, 198 (1970).

40. A. P. Alol'zin, P. Ghosh and Yu. Ya. Kharitonov, $J$. electrochem. Soc. India 33, 177 (1984).

41. S. Yu. Volosova, Z. A. Iofa and T. G. Stepina, Elektrokhimiya 13, 393 (1977).

42. W. E. O'Grady, $J$. electrochem. Soc. 127, 555 (1980).

43. H. Viefhaus and M. Janik-Czachor, Werkst. Korros. 28, 219 (1977). 